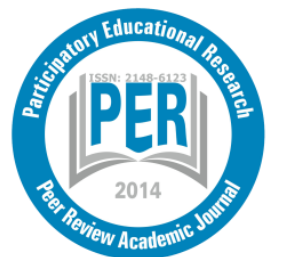

Participatory Educational Research (PER)

Vol. 8(1), pp. 409-422, January 2021

Available online at http://www.perjournal.com

ISSN: 2148-6123

http://dx.doi.org/10.17275/per.21.24.8.1

\title{
High Schoolers' Usage Intensity of Mobile Social Media and Nomophobia: Investigating the Mediating Role of Flow Experience
}

\begin{tabular}{|c|c|}
\hline \multicolumn{2}{|c|}{$\begin{array}{c}\text { Mehmet Kara }{ }^{1} \\
\text { Department of Computer Technology, Amasya University, Amasya, Turkey } \\
\text { ORCID: 0000-0003-2758-2015 }\end{array}$} \\
\hline Article history & This study aimed to investigate the relationship between high so \\
\hline $\begin{array}{l}\text { Received: } \\
23.08 .2020\end{array}$ & $\begin{array}{l}\text { usage intensity of mobile social media and nomophobia through the } \\
\text { mediation of flow experience. By adopting flow as a multidimensional }\end{array}$ \\
\hline $\begin{array}{l}\text { Received in revised form: } \\
03.11 .2020\end{array}$ & $\begin{array}{l}\text { construct; skill, machine interaction, and social interaction were } \\
\text { included in the analysis as the conditions while concentration, } \\
\text { enjoyment, and playfulness were included as the dimensions. A total of }\end{array}$ \\
\hline $\begin{array}{l}\text { Accepted: } \\
03.11 .2020\end{array}$ & $\begin{array}{l}584 \text { adolescent mobile social media users participated in the study. The } \\
\text { proposed model was tested through ordinary least-squares regression }\end{array}$ \\
\hline Key words: & analysis and bootstrap methods. The findings showed that the usage \\
\hline $\begin{array}{l}\text { Mobile media; } \\
\text { Social media; } \\
\text { Flow experience; } \\
\text { Nomophobia; } \\
\text { Adolescents }\end{array}$ & $\begin{array}{l}\text { intensity of the favorite mobile social media significantly predicts both } \\
\text { conditions and dimensions of flow experience and nomophobia. In } \\
\text { addition, the dimensions of flow experience together with skill } \\
\text { significantly mediate the relationship between the usage intensity and } \\
\text { nomophobia while the other conditions do not. These findings imply that } \\
\text { as students spend more time on their favorite mobile social media, their } \\
\text { nomophobic behaviors increase with the mediation of the dimensions } \\
\text { and skill; but not the other conditions. The current study contributes to } \\
\text { the relevant literature by associating nomophobia with flow experience } \\
\text { on multiple mobile social media platforms. It also has implications for } \\
\text { parents, school counselors, and educators of high school students. }\end{array}$ \\
\hline
\end{tabular}

\section{Introduction}

Smartphone usage has become prevalent among adolescents (Lauricella et al. 2014) in addition to other age groups due to the numerous advantages they offer provided by the mobile services. The usage goals could be stated as social media (Deng et al., 2019), games, or study purposes (Seo et al., 2016). The rapidly increasing use of smartphones calls for more attention to media use and usage intensity (Deng et al, 2019) and their relationships with problematic use. In spite of their various advantages, they could also function as a source of several psychological problems such as the problematic smartphone (e.g. Yang et al., 2019; Yildiz Durak, 2019) and internet use (e.g. Škařupová, Ólafsson, \& Blinka, 2016). One of these problems is Nomophobia (NMP), a relatively recent term used to define "the fear of not being able to use a smartphone" (Yildirim \& Correia, 2015, p.136).

The studies revealed that smartphone usage time is associated with NMP (Gezgin, Cakir, \& Yildirim, 2018; Kara, Baytemir, \& Inceman-Kara, 2019) as well as other psychological problems (Khang, Kim, \& Kim, 2013). It was additionally revealed that NMP is associated with

\footnotetext{
${ }^{1}$ Correspondency: m.kara@live.com
} 
other problems such as stress (Tams, Legoux, \& Léger, 2018), loneliness (Kara et al., 2019; Y1ldız Durak, 2018), or anxiety (Kara et al., 2019; King et al., 2013). Research shows that flow experience could result in negative consequences such as problematic internet, games (Khang et al., 2013), and social media use (Huang, Hsieh, \& Wu, 2014). Therefore, the current study focused on the association of usage intensity of mobile social media with NMP through the mediation of flow experience.

In this regard, adolescents' social media use is a research issue that needs further investigation, particularly in the context of problematic use (e.g. Škařupová et al., 2016; Y1ldız Durak, 2018), considering their needs for social relationships in this period (Boffi et al., 2016). Likewise, research shows that social media applications are the most used ones via smartphones (Deng et al., 2019). There is a direct link between new media activities and flow experience (Boffi et al., 2016) and smartphones facilitate access to the new media tools. Rains and Brunner (2015), based on their review on social media studies, conclude that the majority of the studies focus on a single brand (Facebook) and this approach limits the generalizability of the findings from these studies due to such factors as focusing on the unique features of the studied media, potential of that media to become obsolete, or concentrating largely on a specific user group. They further suggest sampling from the users of multiple social media brands for the enhancement of the generalizability of the gathered findings. For this reason, the current study focused on adolescents' usage of and experience on their favorite mobile social media, which enabled to include the users of several social media brands. Based on these considerations, the present study aimed to investigate the relationship between high schoolers' Mobile Social Media Usage (MSMU) and NMP with the mediation of the conditions and dimensions of flow experience (see Figure 1).

\section{Flow Experience}

Flow or the optimal experience has been proposed as a positive psychology construct by Csikszentmihalyi. It can be defined as an experience in which individuals feel deep enjoyment and concentration by losing the sense of time together with the balance between skills and challenges (Csikszentmihalyi, 1990). Csikszentmihalyi (2014, p.133) characterizes flow activities by listing the conditions of flow as follows: "(1) Clear goals (2) Immediate feedback (3) Skill-Challenge Balance (4) Deep Concentration (5) Forgotten Problems (6) Control (7) Disappeared self-consciousness (8) Altered sense of time, and (9) Autotelic experience". Under these conditions, individuals participate in an activity with their internal motivation (Csikszentmihalyi, 2014).

\section{Flow Experience in Web Environments}

Chen (2006) proposed three factors to understand web users' flow experience: (1) experiences, (2) antecedents, and (3) consequences. To understand experiences in web environments, the dimensionality of flow is the first consideration. However, it can be accentuated that a consensus on the dimensionality has not been created in the literature. Several studies adopted flow experience as unidimensional (e.g. Liu et al., 2016; Hoffman \& Novak, 1996), while others assumed it as multidimensional (e.g. Kaur et al., 2016a; Kaur et al., 2016b; Koufaris, 2002). The unidimensional and multidimensional views of flow could still be observed in the relevant literature. The current study adopted flow as a multidimensional construct.

As a matter of fact, there is an ongoing trend in the literature on flow experience to reveal its antecedents and consequences in a web environment. In their first process model, Hoffman and 
Novak (1996) proposed the primary and secondary antecedents of flow experience in computermediated environments. According to this model, the primary antecedents are focused attention and skill-challenge balance while the secondary antecedents are interactivity and telepresence. Further studies indicated that users' daily use of the web and their web experience enhance their skills (Hoffman \& Novak, 2009; Novak, Hoffman, \& Yung, 2000) and challenge/skill balance enhances flow experience, consequently (Koufaris, 2002; Liu et al. 2016). The web experience of the users was also determined as an antecedent of flow in several studies (e.g. Novak et al., 2000).

\section{Flow Experience in Social Media}

Kaur et al. (2016a) differentiated the conditions and dimensions to clarify and elaborate on the flow experience for Facebook. By adopting a multidimensional perspective, they defined dimensions as the components of flow and conditions as the requirements for flow to occur. Kaur et al. (2016a, 2016b) include both conditions and dimensions in their conceptual definition as follows: Skill (SK), Machine Interaction (MI), Social Interaction (SI), Playfulness (PL), Enjoyment (EN), and Concentration (CO). In another study, they (2016b) classified them as conditions (SK, MI, and SI) and dimensions (EN, CO, and PL). Based on the relevant literature, they (2016a, p.363) defined them as follows:

SK: "The user competencies for performing tasks or activities on Facebook"

MI: "The speed of information processing on Facebook"

SI: "The possibility of establishing and maintaining online social relationships with other FB users"

EN: "A personally pleasurable state that includes the intrinsic value attained by using Facebook"

CO: "The state of complete immersion in using Facebook"

PL: "An experiential user state of happiness, excitement, satisfaction, and hope"

A study by Khang et al. (2013) showed that daily time spent on the mobile environment is an antecedent of flow experience, which in turn results in media addiction. Similar to this study and the previously mentioned ones on web environments (Hoffman \& Novak, 2009; Novak et al., 2000), the present study hypothesized that adolescents' MSMU is an antecedent of flow experience by adopting the multidimensional perspective of Kaur et al. (2016a; 2016b). Thus, the hypotheses below were tested in this study:

- Hypothesis 1: High schoolers' MSMU has a significant positive influence on SK.

- Hypothesis 2: High schoolers' MSMU has a significant positive influence on MI.

- Hypothesis 3: High schoolers' MSMU has a significant positive influence on SI.

- Hypothesis 4: High schoolers' MSMU has a significant positive influence on EN.

- Hypothesis 5: High schoolers' MSMU has a significant positive influence on CO.

- Hypothesis 6: High schoolers' MSMU has a significant positive influence on PL.

\section{Flow Experience and Negative Consequences}

Several studies investigated the negative consequences of flow, addictions in particular (e.g. Brailovskaia et al. 2018; Huang, Hsieh, \& Wu, 2014; Stavropoulos et al. 2018). Khang et al. (2013) tested three models for the internet, mobile environment, and video games to reveal the mediation role of flow as a unidimensional construct in the relationship between the factors regarding digital media usage (time spent using media, self-traits, and motives) and media 
addiction. The findings indicated that time spent using media, self-traits, and motives are the antecedents of flow experience and media addiction in all environments and flow mediates the relationship between the factors influencing usage and addiction. A relatively recent study by Stavropoulos et al. (2018) showed that online flow experienced by adolescents is significantly associated with internet addiction. Similarly, Yang et al. (2014) found out that online flow experienced by adolescents is an antecedent of internet addiction. Brailovskaia et al. (2018) explored that social media usage intensity mediates the relationship between flow experience and addiction. In the same vein, several other studies revealed the association of online flow experience with problematic internet (Kim \& Davis 2009) and social media use (Huang et al., 2014). Kaur et al. (2016b) also indicated that adolescents' flow experience on social media is the antecedent of their online regret experience. In this context, the present study hypothesized that NMP is a consequence of the flow experienced by high schoolers in their favorite mobile social media.

\section{Nomophobia}

Nomophobia has emerged as a modern-age phobia and is used as an abbreviation of No mobile phone phobia. It took particular attention by scholars with the widespread usage of smartphones. King, Valença, and Nardi (2010, p. 52) defined it as "the fear of becoming technologically incommunicable, distant from the MP [Mobile Phone] or not connected to the Web". This early definition covered the use of mobile phones, computers, and the web. Yildirim and Correia (2015) redefined NMP by underlining smartphones and the mobile services provided by them.

Several other studies spent particular attention to investigating the antecedents of NMP (e.g. Han, Kim, \& Kim, 2017; Kara et al., 2019) or the associated factors (e.g. Mendoza et al., 2018; Y1ldız Durak, 2018; Yildiz Durak, 2019). First of all, it was currently explored that NMP was closely associated with smartphone (Yildiz Durak, 2019) and internet addictions (Gezgin et al., 2018). Other studies revealed the association of social media usage with NMP (S1rakaya, 2018; Y1ldiz Durak, 2018). It was also found out that smartphone usage duration (Yildirim et al., 2016) and internet ownership duration (Gezgin \& Çakır 2016), and daily smartphone usage intensity (Gezgin et al., 2018; Kara et al., 2019) were associated with NMP. Y1ldız Durak (2018) found out that adolescents' duration of daily social media usage is a predictor of NMP. Besides, Sirakaya (2018) showed that students using smartphones for social media purposes as well as shopping demonstrate more nomophobic behaviors compared with the ones using them for other purposes. Therefore, the present study hypothesized that high schoolers' daily social media usage predicts their NMP. Furthermore, the research indicated that daily media usage (the internet, mobile environment, and video games) is a predictor of the addiction to these media with the mediation of the flow experience (Khang et al., 2013). It was also hypothesized that as high schoolers' MSMU increases, their NMP increase, consequently. It was also assumed that this relationship is mediated by the flow experience. Based on the reviewed literature, this study tested the proposed model in Figure 1 and the following hypotheses were raised with a multidimensional perspective on flow in this study:

- Hypothesis 7: SK in using favorite mobile social media has a significant positive influence on NMP.

- Hypothesis 8: MI during the usage of favorite mobile social media has a significant positive influence on NMP.

- Hypothesis 9: SI through favorite mobile social media has a significant positive influence on NMP. 
- Hypothesis 10: EN experienced while using favorite mobile social media has a significant positive influence on NMP.

- Hypothesis 11: CO experienced while using favorite mobile social media has a significant positive influence on NMP.

- Hypothesis 12: PL experienced while using favorite mobile social media has a significant positive influence on NMP.

- Hypothesis 13: Adolescents' MSMU has a significant positive influence on NMP.

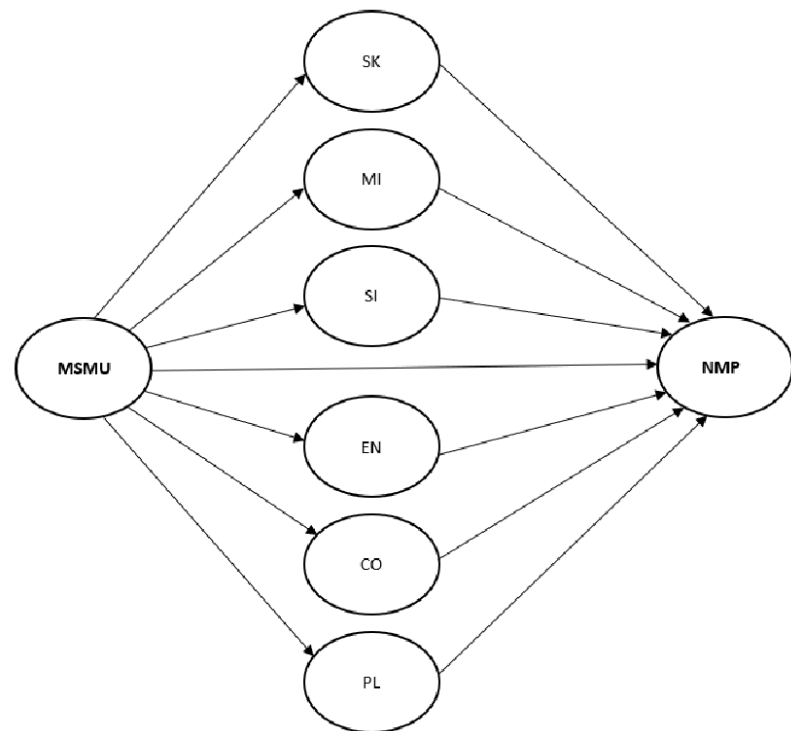

Figure 1. The Hypothesized Model in This Study

\section{Method}

\section{Participants}

The participants of this study are adolescent mobile social media users from the nine high schools in Turkey. The convenience sampling strategy was used to choose the participants of the present study. Since the used sampling strategy requires a detailed description of the participants to allow replication, the demographics of the participants were indicated in Table 1. A total of 602 adolescents voluntarily participated in the study. 12 outliers and six participants who stated that they do not currently have a social media profile were removed from the dataset. Therefore, a total of 584 adolescent mobile social media users were included in the analysis.

Table 1. Demographic Characteristics of the Participants

\begin{tabular}{lll}
\hline & Frequency & Percentage \\
\hline Gender & & \\
Female & 328 & 56.2 \\
Male & 256 & 43.8 \\
Age & & \\
14 & 59 & 10.1 \\
15 & 207 & 35.4 \\
16 & 171 & 29.3 \\
17 & 100 & 17.1 \\
18 & 47 & 8.0 \\
Smartphone Ownership (Year) & & \\
Less than 1 & 140 & 24.0
\end{tabular}




$\begin{array}{lll}1-2 & 155 & 26.5 \\ 2-3 & 130 & 22.3 \\ 3-4 & 65 & 11.1 \\ 4 \text { and more } & 88 & 15.1 \\ \text { Missing } & 6 & 1.0 \\ \text { Social media Ownership (Year) } & & \\ \text { Less than 1 } & 114 & 19.5 \\ 1-2 & 134 & 22.9 \\ 2-3 & 110 & 18.8 \\ 3-4 & 122 & 20.9 \\ 4 \text { and more } & 101 & 17.3 \\ \text { Missing } & 3 & .5\end{array}$

As illustrated in Table 1, 56.2\% of the participants $(\mathrm{N}=328)$ are female and $43.8 \%$ of them $(\mathrm{N}=256)$ are male. Their ages ranged from 14 to 18 and the majority of them are at the age of $15(35.4 \%, \mathrm{~N}=207)$. While $24.0 \%$ of them $(\mathrm{N}=140)$ are smartphone users for less than one year, $15.1 \%$ of them $(\mathrm{N}=88)$ have smartphones for more than four years. Likewise, $19.5 \%$ of the participants $(\mathrm{N}=114)$ have social media profile for less than one year and $17.3 \%$ of them $(\mathrm{N}=101)$ are social media users for more than four years. There were missing values for smartphone ownership, social media ownership, and favorite social media. However, the data obtained from these participants were included in the analysis as they stated that they have a smartphone and social media profile.

\section{Instruments}

The questionnaire, distributed to the high schoolers, included three parts: (1) Participant information form (2) Flow experience scale for favorite mobile social media, and (3) NMP questionnaire.

Participant Information Form: The form was used to collect demographic data from the participants. The data for their MSMU were collected in this part. Additionally, the demographic data about the participant students (age, gender, and duration of smartphone and social media profile ownership) were collected in this part of the questionnaire.

Flow Experience Scale for Favorite Mobile Social Media: The scale was originally developed by Kaur et al. (2016a) to measure adolescents' flow experience on Facebook. It included 26 items and six factors: SK, MI, SI, PL, EN, and CO. The scale was used in the current study as multidimensional. In the development study, the factor loadings of the items ranged from .58 to .80 as a result of the exploratory factor analysis and .69 to .83 as a result of confirmatory factor analysis. The Cronbach Alpha values obtained for the factors in the scale ranged from .77 to .90 and the value obtained for the overall scale was .92 . These values indicated satisfactory reliability for the scale and the factors.

The scale was adapted to both the Turkish language and in a way that it includes participants' favorite mobile social media for the current study, instead of using it only for Facebook. The language equivalency was provided by back translation strategy. The scale was translated into Turkish by a professional from English Language Teaching and translated back to English by another professional from the same department. The items were compared and confirmed in terms of their meanings. As a result of the confirmatory factor analysis conducted in this study,

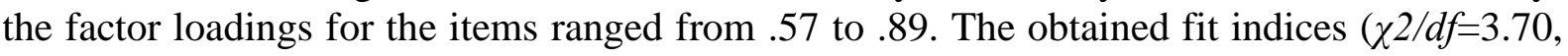
$\mathrm{CFI}=.92, \mathrm{AGFI}=.85, \mathrm{SRMR}=.07, \mathrm{RMSEA}=.07)$ showed adequate model fit (Hu \& Bentler, 1999). The Cronbach Alpha values were computed for each factor and the overall scale. The 
obtained values for the factors $(\mathrm{SK}=.85, \mathrm{MI}=.82, \mathrm{SI}=.82, \mathrm{EN}=.83, \mathrm{CO}=.87, \mathrm{PL}=.91)$ and the overall scale (.92) showed that the adapted scale is sufficiently reliable according to Field (2013). In addition, the computed corrected item-total correlations, which ranged from .43 to .60 , indicated adequate reliability in terms of item consistency according to Field's (2013) criterion that this value is required to be greater than .30 for a scale to be reliable. The adapted 26-item scale was distributed to the participants as a 5-point Likert-type scale, where 1 referred to "Strongly disagree" and 5 referred to "strongly agree". An example item is as follows: "I feel the most relaxed when using my favorite mobile social media application."

NMP Questionnaire: The questionnaire developed and validated by Yildirim and Correia (2015) was used to collect data about adolescents' NMP levels. The questionnaire included 20 items and four factors. However, it was used as a unidimensional construct in the current study. In the development study by Yildirim and Correia (2015), the factor loadings of the items were obtained in the range of .47 to .86. The Cronbach Alpha value for the questionnaire was obtained as .95. The Turkish version of the questionnaire was validated by Yildirim et al. (2016). The analysis for the construct validity of the adapted questionnaire indicated adequate fit. The Cronbach Alpha coefficient was .92, which indicates its reliability at a satisfactory level. The questionnaire was distributed to the participants in the form of a 5-point Likert-type scale, where 1 and 5 referred to "strongly disagree" and "strongly agree", respectively. The items in the questionnaire can be exemplified as follows: "I would feel uncomfortable without constant access to information through my smartphone".

\section{Data Analysis}

The proposed model was tested through the Ordinary Least-Squares (OLS) regression analysis as well as bootstrapping through PROCESS macro by Hayes (2012; 2013). Besides, descriptive statistics and Pearson's product-moment correlation analyses were used to summarize and interpret the collected data. The data were firstly checked for missing data. As the percentage of missing data was less than 5\%, they were replaced with series mean (Tabachnick \& Fidell, 2013). However, the missing data in MSMU were excluded from the analysis $(\mathrm{N}=6)$. The data were secondly screened for the outliers and a total of 12 outliers were removed from the dataset. Thus, a total of 584 participant responses were included in the analysis. As OLS is a robust method for normality assumption (Hayes, Montoya, \& Rockwood, 2017), only skewness and kurtosis values (see Table 2) and histograms of the measured constructs were checked. Finally, the data were screened for multicollinearity assumption. As the correlation coefficients among the variables are in the range of .087 to .691 (see Table 3), it was assumed that the multicollinearity assumption was met.

As stated above, the hypothesized model was tested through the OLS regression and bootstrapping. MSMU was used as the predictor variable while conditions and dimensions of flow experience were used as the mediator variables. NMP was used as the dependent variable in the model. The analysis was conducted by running "multiple mediation model 4 " via the PROCESS macro software (Hayes, 2012). The model was tested with 5000 bootstrap samples. The significance of the model was tested at .05 level of significance based on the criterion that the Confidence Intervals (CI) do not contain zero (Hayes, 2013). Finally, pairwise contrasts among the mediating variables were conducted to identify the strongest mediator in the relationship between MSMU and NMP. 


\section{Findings}

\section{Descriptive Findings}

The descriptive findings on the variables in the study were shown in Table 2 . The mean scores of the students' MSMU were obtained as $3.050(S D=1.514)$. Adolescents have moderate NMP according to their scores on the NMP questionnaire $(M=2.943, S D=.932)$. In terms of the dimensions of flow experience, the largest mean score was obtained for SI $(M=3.539$, $S D=1.192)$, followed by SK $(M=3.477, S D=1.062)$, and the lowest mean score was obtained for $\mathrm{CO}(M=2.569, S D=1.141)$, followed by PL $(M=2.715, S D=1.158)$.

Table 2. Descriptive Findings for the Variables in the Model

\begin{tabular}{lllll}
\hline Variables & $\boldsymbol{M}$ & $\boldsymbol{S D}$ & Skewness & Kurtosis \\
\hline 1. MSMU & 3.050 & 1.514 & -.004 & -1.482 \\
2. NMP & 2.943 & .932 & .109 & -.604 \\
3. SK & 3.477 & 1.062 & -.431 & -.752 \\
4. MI & 3.291 & 1.045 & -.343 & -.622 \\
5. SI & 3.539 & 1.192 & -.463 & -.863 \\
6. EN & 3.405 & 1.181 & -.298 & -.841 \\
7. CO & 2.569 & 1.141 & .469 & -.738 \\
8. PL & 2.715 & 1.158 & .244 & -.839 \\
N=584 & & & & \\
\hline
\end{tabular}

\section{Hypotheses Testing}

The correlations among the variables were determined using Pearson's ProductMoment correlation analysis. The findings firstly indicated a significant positive correlation between MSMU and NMP $(r=.133 p<.01)$. The relationships between MSMU and the variables of SK $(r=.267 p<.01)$, MI $(r=.200 p<.01)$, SI $(r=.285 p<.01), \mathrm{EN}(r=.096 p<.05), \mathrm{CO}(r=.087$ $p<.05)$, and PL $(r=.167 p<.01)$ were also found as positive and significant as indicated in Table 3. Furthermore, the relationships between NMP and the dimensions of SK ( $r=.315 p<.01)$, MI $(r=.242 p<.01)$, SI $(r=.309 p<.01)$, EN $(r=.436 p<.05), \mathrm{CO}(r=.517 p<.05)$, and PL $(r=.567$ $p<.01)$ were obtained as positive and significant.

Table 3. Obtained Correlation Coefficients among the Variables

\begin{tabular}{|c|c|c|c|c|c|c|c|c|}
\hline Variables & 1 & 2 & 3 & 4 & 5 & 6 & 7 & $\overline{8}$ \\
\hline 1. MSMU & - & & & & & & & \\
\hline 2. NMP & $.133 * *$ & - & & & & & & \\
\hline 3. SK & $.267 * *$ & $.315^{* *}$ & - & & & & & \\
\hline 4. MI & $.200 * *$ & $.242 * *$ & $.553 * *$ & - & & & & \\
\hline 5. SI & $.285^{* *}$ & $.309 * *$ & $.529 * *$ & $.485^{* *}$ & - & & & \\
\hline 6. EN & $.096^{*}$ & $.436 * *$ & $.525^{* *}$ & $.388 * *$ & $.600 * *$ & - & & \\
\hline 7. $\mathrm{CO}$ & $.087 *$ & $.517 * *$ & $.180 * *$ & $.177 * *$ & $.176^{* *}$ & $.369 * *$ & - & \\
\hline $\begin{array}{l}\text { 8. PL } \\
\mathrm{N}=584\end{array}$ & $.167 * *$ & $.567 * *$ & $.199 * *$ & $.183 * *$ & $.238 * *$ & $.337 * *$ & $.691 * *$ & - \\
\hline
\end{tabular}

$N=584, * p<.05, * * p<.01, * * * p<.001$

The total and direct effects among the variables were demonstrated in Figure 2 . The total effects of MSMU on NMP was obtained as positive and significant $(c=.082, S E=.026, t=3.190$, $p=.006$ ). This finding implies that the participants with high scores of MSMU are more likely to have high scores of NMP. The direct effects of MSMU on the mediator variables of SK $(B=.187, S E=.028, t=6.606, p=.000)$, MI $(B=.138, S E=.028, t=4.894, p=.000)$, SI $(B=.225$, 
$S E=.031, t=7.281, p=.000), \mathrm{EN}(B=.075, S E=.032, t=2.320, p=.021), \mathrm{CO}(B=.066, S E=.031$, $t=2.125, p=.034)$, and PL $(B=.128, S E=.031, t=4.140, p=.000)$ were also positive and significant. Similarly, these findings indicate that the participants who have higher mean scores of MSMU are more likely to have higher scores for the conditions and dimensions of flow experience.

Figure 2 further demonstrates the direct effects of the mediating variables on the dependent variable. The direct effects of the mediator variables of $\mathrm{EN}(B=.140, S E=.039, t=3.315$, $p=.000), \mathrm{CO}(B=.150, S E=.040, t=3.785, p=.000)$, and PL $(B=.283, S E=.038, t=7.451$, $p=.000)$ on NMP were positive and significant. In other words, the dimensions of flow significantly predict NMP. However, the conditions of flow, except SK, does not predict NMP. While the direct effect of SK $(B=.085, S E=.040, t=2.118, p=.035)$ is significant, the direct effects of MI $(B=.006, S E=.040, t=.160, p=.873)$, and SI $(B=.023, S E=.039, t=.592, p=.554)$ on NMP were non-significant at the .05 level of significance. These findings show that the ones with higher scores on the dimensions of flow as well as SK are more likely to have higher scores for NMP while the ones with higher scores on the conditions of flow are not.

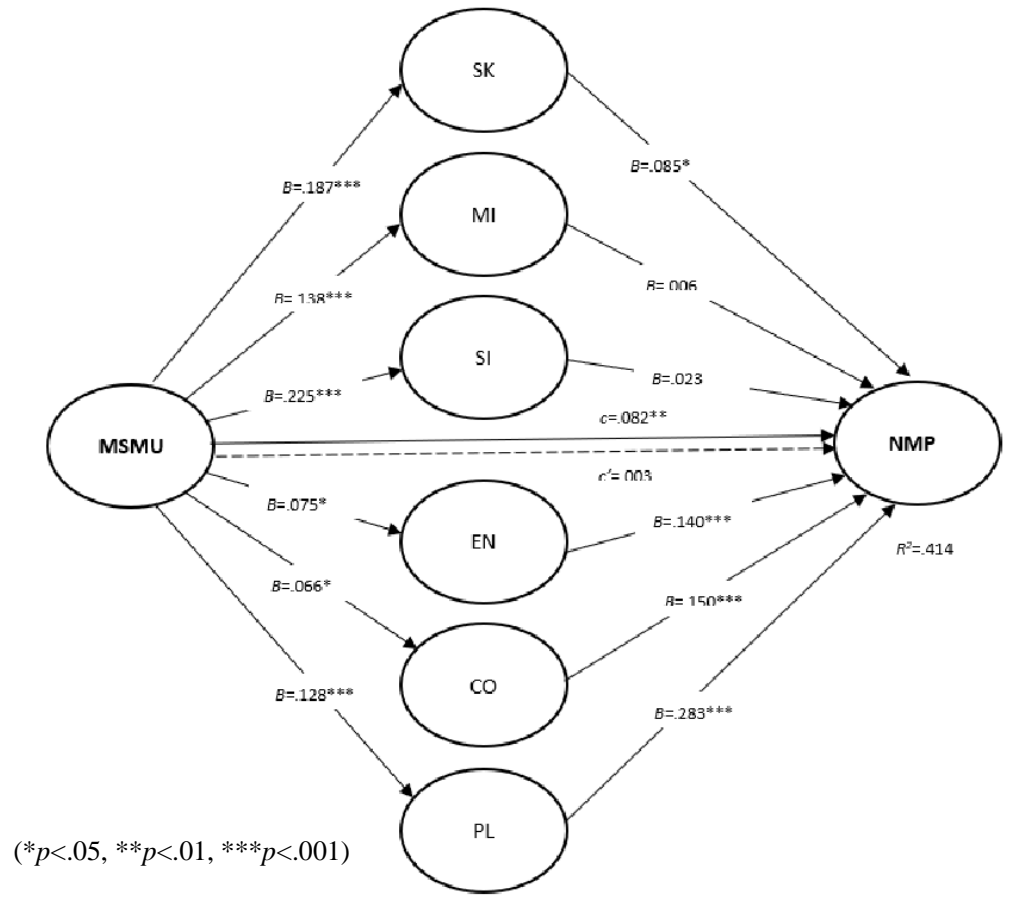

Figure 2. Mediation of Flow Experience between MSMU and NMP

The multiple mediation analysis revealed that the direct effect of MSMU on NMP decreased and became non-significant $\left(c^{\prime}=.003, S E=.021, t=.156, p=.876\right)$. This finding revealed the significant mediating effects of the dimensions of flow experience. In the same vein, it was found out that the dimensions of flow experience together with SK are significant mediators in the relationship between MSMU and NMP $(F(7-576)=51.424, p=.000)$. In other saying, the total model is significant and NMP accounts for $41.4 \%$ of the total variance $\left(R^{2}=.414\right)$.

The indirect effects of MSMU on NMP were also shown in Table 4. The indirect effect of MSMU on NMP via the dimensions of flow experience was obtained as significant $(B=.079$, CI $[.0423, .1168])$. The indirect effects of MSMU on NMP through SK $(B=.016$, CI [.002, $.033]), \mathrm{EN}(B=.011, \mathrm{CI}[.002, .023]), \mathrm{CO}(B=.010, \mathrm{CI}[.006, .023])$, and PL $(B=.036, \mathrm{CI}[.019$, $.060])$ were obtained as significant. 
Table 4. Prediction of NMP by MSMU with the Mediation of Flow Experience

\begin{tabular}{|c|c|c|c|c|c|c|}
\hline \multirow{2}{*}{\multicolumn{2}{|c|}{ Indirect Effects }} & & \multicolumn{4}{|c|}{ Bootstrapping } \\
\hline & & & $B$ & $S E$ & Lower & Upper \\
\hline \multicolumn{3}{|c|}{ Total Indirect Effect } & .079 & .019 & .042 & .117 \\
\hline MSMU & $\rightarrow$ & $\mathrm{SK} \longrightarrow \mathrm{NMP}$ & .016 & .008 & .002 & .033 \\
\hline MSMU & $\rightarrow$ & $\mathrm{MI} \longrightarrow \mathrm{NMP}$ & .001 & .006 & -.001 & .013 \\
\hline MSMU & $\longrightarrow$ & $\mathrm{SI} \mathrm{NMP}$ & .005 & .009 & -.012 & .022 \\
\hline MSMU & $\longrightarrow$ & $\mathrm{EN} \longrightarrow \mathrm{NMP}$ & .011 & .006 & .002 & .023 \\
\hline MSMU & $\rightarrow$ & $\mathrm{CO} \longrightarrow \mathrm{NMP}$ & .010 & .005 & .006 & .023 \\
\hline MSMU & $\rightarrow$ & $\mathrm{PL} \longrightarrow \mathrm{NMP}$ & .036 & .010 & .019 & .060 \\
\hline \multicolumn{7}{|c|}{ Contrasts } \\
\hline \multicolumn{3}{|c|}{ MI X PL } & -.035 & .012 & -.061 & -.013 \\
\hline \multicolumn{3}{|c|}{ SI $\mathbf{X}$ PL } & -.031 & .013 & -.058 & -.006 \\
\hline \multicolumn{3}{|c|}{ EN X PL } & -.026 & .010 & -.048 & -.008 \\
\hline \multicolumn{3}{|c|}{ CO X PL } & -.026 & .010 & -.048 & -.010 \\
\hline
\end{tabular}

$\mathrm{N}=584, * p<.05, * * p<.01, * * * p<.001$

However, the indirect effects of MSMU on NMP via MI ( $B=.001$, CI $[-.001, .013])$ and SI $(B=.005, \mathrm{CI}[-.012, .022])$ were found as non-significant. These findings suggest that the single inclusion of the dimensions of flow and SK in the model significantly mediates the MSMUNMP relationship while the single inclusion of MI and SI does not.

Table 4 finally demonstrated the pairwise contrasts among the single mediating variables. The analysis indicated significant differences in four paired contrasts. The indirect effect of PL (.036) was significantly stronger than that of MI (.001), SI (.005), EN (.011), and CO (.010).

\section{Discussion and Conclusion}

This study investigated the association of high schoolers' MSMU with NMP via the mediation of flow experience. In this regard, several hypotheses were tested through the proposed model (see Figure 2). The findings firstly indicated that MSMU predicts both conditions (SK, MI, SI) and dimensions (EN, CO, PL) of flow. In conjunction with the previous studies (Hoffman \& Novak, 2009; Khang et al., 2013), the findings showed that MSMU is an antecedent of flow experience. According to Csikszentmihalyi (1990), flow activities require the rules for flow to occur: improvement of skills, clearly identified goals, feedback on the activity, and the possibility of control on it. Thus, the current study confirmed that MSMU provides adolescents with improved skills, which enable them to have improved control of the activities on their favorite social media, and increased perception of feedback on the activities through MI and SI. Together with the improved SK (competencies), MI (information processing speed), and SI (establishment and maintenance of social relationships), the participant students concurrently felt improved flow in terms of EN (the state of pleasure), CO (the state of complete involvement), and PL (the state of happiness, satisfaction, etc.), as a result of the usage of their favorite mobile social media.

Secondly, the current study revealed that MSMU is an antecedent of NMP. The mediation analysis indicated the direct significant effect of MSMU on NMP. The obtained finding is congruent with the prior studies on NMP, which showed daily usage is a cause of NMP (Kara et al., 2019; Y1ldiz Durak, 2018). This finding is also consistent with the previous studies demonstrating that daily usage is a cause of smartphone, the internet (Khang et al., 2013), and social media addictions (Brailovskaia, Margraf, \& Köllner, 2019). Therefore, it was concluded that the morehigh schoolers use their favorite mobile social media daily, the more likely they 
are to show nomophobic behaviors.

Thirdly, the mediation analysis through the proposed model illustrated that the dimensions of flow experience together with SK significantly mediates the relationship between MSMU and NMP. Additionally, flow experience is an antecedent of NMP as is an antecedent of problematic internet use (Kim \& Davis 2009; Stavropoulos et al., 2018; Yang et al., 2014); and the conditions of flow (MI, and SI) were found as non-significant. In a similar study, Khang et al. (2013) revealed the significant mediation of flow experience, adopted as unidimensional, in the relationship of usage intensity and media addictions (the internet, mobile, and game environments). The present study, on the other hand, elucidated this finding by assuming flow as multidimensional. Accordingly, it was inferred that the feelings of the flow states (EN, CO, PL) cause NMP while the conditions or the rules required for the flow activities to occur (MI, SI) (Csikszentmihalyi, 1990) do not. As Khang et al. (2013) concluded for several environments; it could be inferred that as users spend more time on their favorite mobile social media, they are likely to feel more satisfaction and diminished stress and look for the stronger stimuli (spending more time through the repeated use), which in turn, causes problematic behaviors, NMP in this case.

Finally, the single inclusion of the mediating variables into the model showed four significant single mediators (SK, EN, CO, and PL). According to the contrasts among them, the single inclusion of PL is the strongest mediator of the relationship between MSMU and NMP. In other saying, PL, the "state of happiness, excitement, satisfaction, and hope" (Kaur et al., 2016a, p.363), compared with other dimensions and conditions, might be demonstrated as the best mediator of the MSMU-NMP relationship.

\section{Recommendations for Practice and Future Studies}

The current study investigated the antecedents of NMP by testing the proposed model. It was found out that as high schoolers spend more time on their favorite mobile social media, they are likely to feel more flow, which in turn, results in NMP. Considering the time spent on the favorite mobile social media as the stimulus, improvement of their self-regulation over their usage duration might be influential on diminishing nomophobic symptoms as also suggested by the prior studies for smartphone addiction (e.g. Gökçearslan et al. 2016). For this reason, the findings of the current study provide parents, school counselors, and educators with implications to support adolescents in improving their self-regulation skills and self-reflection on their mobile social media usage. For instance, a study conducted by Yang et al. (2014) showed that the support from the parents significantly decreased adolescents' internet addiction and improved their exploratory behavior.

As Csikszentmihalyi (2014) stated flow is like energy and could be used to produce both positive and negative behaviors. Then, flow activities could result in either positive outcomes such as personal development, well-being in daily life (Delle Fave \& Bassi, 2016), and exploratory behavior (Yang et al., 2014) or problematic behaviors such as addictions (Khang et al., 2013) and NMP. Therefore, the findings from this study additionally imply that adolescents' energy, or flow, is required to be directed into the activities both in and out of school that would result in positive outcomes in the long run. This could be achieved, as Csikszentmihalyi (2014) suggested, with the inclusion of more motivational aspects into education and extracurricular activities.

The current study was conducted with convenience sampling, a non-random sampling strategy. Thus, it is recommended to conduct replication studies with the adolescents for the 
generalizability of the findings from this study. Additionally, a similar replication study might be conducted with the participants from other populations such as university students or adults. This study concentrated solely on mobile social media usage. Future studies might focus on mobile games, which have similar potential to produce a flow experience with social media. Finally, it is recommended to improve the model proposed in this study with the inclusion of the variables used in the relevant studies such as self-traits, motives (Khang et al., 2013), personality (Brailovskaia et al., 2019) or self-regulation (Gökçearslan et al., 2016).

\section{References}

Boffi, M., Riva, E., Rainisio, N., \& Inghilleri, P. (2016). Social psychology of flow: A situated framework for optimal experience. In L. Harmat et al. (Eds.) Flow experience: Empirical research and applications (pp. 215-231). Springer. doi:10.1007/978-3-31928634-1

Brailovskaia, J., Margraf, J., \& Köllner, V. (2019). Addicted to Facebook? Relationship between Facebook Addiction Disorder, duration of Facebook use and narcissism in an inpatient sample. Psychiatry Research, 273, 52-57. doi:10.1016/j.psychres.2019.01.016

Brailovskaia, J., Rohmann, E., Bierhoff, H. W., \& Margraf, J. (2018). The brave blue world: Facebook flow and Facebook Addiction Disorder (FAD). PloS One, 13(7), 1-12. doi:10.1371/journal.pone.0201484

Chen, H. (2006). Flow on the net-detecting Web users' positive affects and their flow states. Computers in Human Behavior, 22(2), 221-233. doi:10.1016/j.chb.2004.07.001

Csikszentmihalyi, M. (1990). Flow: The psychology of optimal experience. New York, NY:Harper \& Row.

Csikszentmihalyi, M. (2014). Applications of flow in human development and education. New York, NY:Springer.

Delle Fave, A. \& Bassi, M. (2016). Flow and psychological selection. In L. Harmat et al. (Eds.) Flow experience: Empirical research and applications (pp. 3-19). Springer. doi:10.1007/978-3-319-28634-1

Deng, T., Kanthawala, S., Meng, J., Peng, W., Kononova, A., Hao, Q., ... \& David, P. (2019). Measuring smartphone usage and task switching with log tracking and self-reports. Mobile Media \& Communication, 7(1), 3-23. doi:10.1177/2050157918761491

Field, A. (2013). Discovering statistics using IBM SPSS statistics. London: Sage.

Gezgin, D. M., Cakir, O., \& Yildirim, S. (2018). The relationship between levels of nomophobia prevalence and internet addiction among high school students: The factors influencing Nomophobia. International Journal of Research in Education and Science, 4(1), 215-225. doi:10.21890/ijres.383153.

Gezgin, D. M., \& Cakir, O. (2016). Analysis of nomofobic behaviors of adolescents regarding various factors. Journal of Human Sciences, 13(2), 2504-2519. doi:10.14687/jhs.v13i2.3797

Gokcearslan, S., Mumcu, F. K., Haslaman, T., \& Cevik, Y. D. (2016). Modelling smartphone addiction: The role of smartphone usage, self-regulation, general self-efficacy and cyberloafing in university students. Computers in Human Behavior, 63, 639-649. doi:10.1016/j.chb.2016.05.091

Han, S., Kim, K. J., \& Kim, J. H. (2017). Understanding nomophobia: Structural equation modeling and semantic network analysis of smartphone separation anxiety. Cyberpsychology, Behavior, and Social Networking, 20(7), 419-427. doi:10.1089/cyber.2017.0113 
Hayes, A. F. (2012). PROCESS: A versatile computational tool for observed variable mediation, moderation, and conditional process modeling. Retrieved from http://processmacro.org/download.html

Hayes, A. F. (2013). Introduction to mediation, moderation, and conditional process analysis: A regression-based approach. New York: Guilford Press.

Hayes, A. F., Montoya, A. K., \& Rockwood, N. J. (2017). The analysis of mechanisms and their contingencies: PROCESS versus structural equation modeling. Australasian Marketing Journal, 25(1), 76-81. doi:10.1016/j.ausmj.2017.02.001

Hoffman, D. L. \& Novak, T. P. (1996). Marketing in hypermedia computer-mediated environments: Conceptual foundations. Journal of Marketing, 60(3), 50-68. doi:10.1177/002224299606000304

Hoffman, D. L., \& Novak, T. P. (2009). Flow online: Lessons learned and future prospects. Journal of Interactive Marketing, 23(1), 23-34. doi:10.1016/j.intmar.2008.10.003

Hu, L. T., \& Bentler, P. M. (1999). Cutoff criteria for fit indexes in covariance structure analysis: Conventional criteria versus new alternatives. Structural Equation Modeling: A Multidisciplinary Journal, 6(1), 1-55.doi:10.1080/10705519909540118

Huang, L. Y., Hsieh, Y. J., \& Wu, Y. C. J. (2014). Gratifications and social network service usage: The mediating role of online experience. Information \& Management, 51(6), 774-782. doi:10.1016/j.im.2014.05.004

Kara, M., Baytemir, K., \& Inceman-Kara, F. (2019). Duration of daily smartphone usage as an antecedent of nomophobia: Exploring multiple mediation of loneliness and anxiety. Behaviour \& Information Technology, 1-14. doi:10.1080/0144929X.2019.1673485

Kaur, P., Dhir, A., Chen, S., \& Rajala, R. (2016a). Flow in context: Development and validation of the flow experience instrument for social networking. Computers in Human Behavior, 59, 358-367. doi:10.1016/j.chb.2016.02.039

Kaur, P., Dhir, A., Chen, S., \& Rajala, R. (2016b). Understanding online regret experience using the theoretical lens of flow experience. Computers in Human Behavior, 57, 230239. doi:10.1016/j.chb.2015.12.041

Khang, H., Kim, J. K., \& Kim, Y. (2013). Self-traits and motivations as antecedents of digital media flow and addiction: The Internet, mobile phones, and video games. Computers in Human Behavior, 29(6), 2416-2424. doi:10.1016/j.chb.2013.05.027

Kim, H. K., \& Davis, K. E. (2009). Toward a comprehensive theory of problematic Internet use: Evaluating the role of self-esteem, anxiety, flow, and the self-rated importance of Internet activities. Computers in Human Behavior, 25(2), 490-500. doi:10.1016/j.chb.2008.11.001

King, A. L. S., Valença, A. M., \& Nardi, A. E. (2010). Nomophobia: the mobile phone in panic disorder with agoraphobia: reducing phobias or worsening of dependence?. Cognitive and Behavioral Neurology, 23(1), 52-54. doi:10.1097/WNN.0b013e3181b7eabc

King, A. L. S., Valença, A. M., Silva, A. C. O., Baczynski, T., Carvalho, M. R., \& Nardi, A. E. (2013). Nomophobia: Dependency on virtual environments or social phobia?. Computers in Human Behavior, 29(1), 140-144. doi:10.1016/j.chb.2012.07.025

Koufaris, M. (2002). Applying the technology acceptance model and flow theory to online consumer behavior. Information Systems Research, 13(2), 205-223. doi:10.1287/isre.13.2.205.83

Lauricella, A. R., Cingel, D. P., Blackwell, C., Wartella, E., \& Conway, A. (2014). The mobile generation: Youth and adolescent ownership and use of new media. Communication Research Reports, 31(4), 357-364. doi:10.1080/08824096.2014.963221

Liu, H., Chu, H., Huang, Q., \& Chen, X. (2016). Enhancing the flow experience of consumers in China through interpersonal interaction in social commerce. Computers in Human Behavior, 58, 306-314. doi:10.1016/j.chb.2016.01.012 
Mendoza, J. S., Pody, B. C., Lee, S., Kim, M., \& McDonough, I. M. (2018). The effect of cellphones on attention and learning: The influences of time, distraction, and nomophobia. Computers in Human Behavior, 86, 52-60. doi:10.1016/j.chb.2018.04.027

Novak, T. P., Hoffman, D. L., \& Yung, Y. F. (2000). Measuring the customer experience in online environments: A structural modeling approach. Marketing Science, 19(1), 22-42. doi:10.1287/mksc.19.1.22.15184

Rains, S. A., \& Brunner, S. R. (2015). What can we learn about social network sites by studying Facebook? A call and recommendations for research on social network sites. New Media \& Society, 17(1), 114-131. doi:10.1177/1461444814546481

Seo, D. G., Park, Y., Kim, M. K., \& Park, J. (2016). Mobile phone dependency and its impacts on adolescents' social and academic behaviors. Computers in Human Behavior, 63, 282-292. doi:10.1016/j.chb.2016.05.026

Sirakaya, M. (2018). Examination of associate students' nomophobia levels according to smartphone use. Mersin University Journal of the Faculty of Education, 14(2), 714-727. doi:10.17860/mersinefd.359458

Škařupová, K., Ólafsson, K., \& Blinka, L. (2016). The effect of smartphone use on trends in European adolescents' excessive Internet use. Behaviour \& Information Technology, 35(1), 68-74. doi:10.1080/0144929X.2015.1114144

Stavropoulos, V., Griffiths, M. D., Burleigh, T. L., Kuss, D. J., Doh, Y. Y., \& Gomez, R. (2018). Flow on the Internet: a longitudinal study of Internet addiction symptoms during adolescence. Behaviour \& Information Technology, 37(2), 159-172. doi:10.1080/0144929X.2018.1424937

Tabachnick, B. G., \& Fidell, L. S. (2013). Using multivariate statistics (6th ed.). Boston, MA:Pearson.

Tams, S., Legoux, R., \& Léger, P. M. (2018). Smartphone withdrawal creates stress: A moderated mediation model of nomophobia, social threat, and phone withdrawal context. Computers in Human Behavior, 81, 1-9. doi:10.1016/j.chb.2017.11.026

Yang, S., Lu, Y., Wang, B., \& Zhao, L. (2014). The benefits and dangers of flow experience in high school students' internet usage: The role of parental support. Computers in Human Behavior, 41, 504-513.doi:10.1016/j.chb.2014.09.039

Yang, X., Zhou, Z., Liu, Q., \& Fan, C. (2019). Mobile phone addiction and adolescents' anxiety and depression: The moderating role of mindfulness. Journal of child and family studies, 28(3), 822-830. doi:10.1007/s10826-018-01323-2

Yildirim, C., \& Correia, A. P. (2015). Exploring the dimensions of nomophobia: Development and validation of a self-reported questionnaire. Computers in Human Behavior, 49, 130137. doi:10.1016/j.chb.2015.02.059

Yildirim, C., Sumuer, E., Adnan, M., \& Yildirim, S. (2016). A growing fear: Prevalence of nomophobia among Turkish college students. Information Development, 32(5), 13221331. doi:10.1177/0266666915599025

Yildiz Durak, H. (2018). What would you do without your smartphone? Adolescents' social media usage, locus of control, and loneliness as a predictor of nomophobia. Addicta: The Turkish Journal on Addictions, 5(3), 543-557. doi:10.15805/addicta.2018.5.3.0025

Yildiz Durak, H. (2019). Investigation of nomophobia and smartphone addiction predictors among adolescents in Turkey: Demographic variables and academic performance. The Social Science Journal, 56(4), 492-517. doi:10.1016/j.soscij.2018.09.003 